\title{
IMPLEMENTASI ADAPTIVE HYPERMEDIA SYSTEM BERBASIS MOODLE UNTUK MENGATASI KERAGAMAN GAYA BELAJAR PADA PENDIDIKAN VOKASI
}

\author{
R. Irlanto Sudomo, Toni Setiawan \\ Universitas IVET \\ Email: irlands082@gmail.com
}

\begin{abstract}
ABSTRAK
Penelitian ini bertujuan untuk mendeskripsikan implementasi Adaptive Hypermedia System Berbasis Moodle dilihat dari aspek: (1) Keragaman Gaya Belajar siswa berupa Visual, Auditory Kinestetik (2) Perencanaan pembelajaran, (3) Pelaksanaan pembelajaran, (4) Sistem penilaian. Penelitian ini dilaksanakan menggunakan pendekatan deskriptif kualitatif. Penelitian yang dilakukan berupaya mendeskripsikan secara jelas mengenai implementasi Hypermedia System Berbasis Moodle di Universitas IVET. Metode yang digunakan untuk mengumpulkan data penelitian adalah 1) metode observasi, 2) metode wawancara, 3) metode dokumentasi. Teknik keabsahan data yang digunakan dalam penelitian ini adalah menggunakan teknik trianggulasi metode dan sumber. Hasil penelitian: (1) gaya belajar mahasiswa Pendidikan Teknik Mesin konsentrasi Otomotif (PTM-O) memiliki latar belakang pendidikan yang heterogen (2) Perencanaan Adaptive Hypermedia System Berbasis Moodle meliputi mempersiapkan Sarana dan prasarana berupa komputer yang ada di laboratorium komputer sebanyak 33 unit, beserta jaringan internet yang tersedia dengan kecepatan 50 mbps. (3) Pelaksanaan pembelajaran dosen melakukan aktifitas pembelajaran sesuai dengan mata kuliah yang diampu. Dosen mengunggah materi pada setiap pertemuan. (4) Sistem Penilaian dalam pembelajaran Adaptive Hypermedia System Berbasis Moodle bisa dilakukan menggunakan quiz.
\end{abstract}

Kata kunci: Adaptive Hypermedia System, Moodle, Gaya Belajar

\begin{abstract}
This study was designed to describe the implementation of Moodle-based Hypermedia Adaptive System seen from aspects: (1) Diversity of Student Learning Styles consisting of Visual, Auditory Kinesthetic (2) Learning planning, (3) Implementation of learning, (4) Learning Systems. This research was conducted using descriptive qualitative discussion. The research conducted agreed to describe in full the implementation of the Moodle-based Hypermedia System at IVET University. The method used to collect research data is 1) observation method, 2) interview method, 3) documentation method. The data validity technique used in this study uses the triangulation technique of methods and sources. The results of the study: (1) the learning styles of students of Automotive Mechanical Engineering Education (PTM-O) have heterogeneous educational backgrounds (2) Planning of MoodleBased Adaptive Hypermedia System prepares facilities and infrastructure that provides computers in a computer laboratory of 33 units, Through an internet network that is available at 50 mbps. (3) Implementation of learning lecturers carry out learning in accordance with the subjects they teach. The lecturer uploads the material at each meeting. (4) Moodle-Based Adaptive Hypermedia Adaptation System Learning can be done using quizzes

Keywords: Adaptive Hypermedia System, Moodle, Learning Styles
\end{abstract}




\section{PENDAHULUAN}

Revolusi industri 4.0 telah merubah peran manusia dalam kehidupan sehari-hari sehingga kehadiran era revolusi industri 4.0 banyak menawarkan berbagai macam potensi. Beberapa tantangan muncul, bahkan saat ini, dalam perkembangan era revolusi industri 4.0. Kecerdasan Buatan (AI), data dan informasi (big data), komputasi awan (cloud technology), internet, uang digital (bitcoin), sosial media hingga keamanan data adalah tantangan yang harus bisa dihadapi para lulusan perguruan tinggi saat ini.

Dengan hadirnya revolusi industri Perguruan tinggi juga dituntut merumuskan proses pendidikan yang dapat mengembangkan karakter para peserta didik. Sebab karakter merupakan satu modal penting untuk kesuksesan mereka. Lulusan yang unggul, harus memiliki karakter positif dan berkualitas. Berkaca dari bangsa Jepang yang mampu bangkit setelah hancur karena perang dunia II, bangsa Korea yang memperjuangkan kemerdekaannya 72 lalu mampu bangkit menjadi negara maju dan produktif.

Untuk mengimplemetasikan Adaptive Hypermedia System Berbasis Moodle, minimal ada tiga komponen pembentuk Adaptive Hypermedia System, yaitu: 1) Infrastruktur Adaptive Hypermedia System Berbasis Moodle, yaitu dapat berupa personal computer (PC), jaringan komputer, internet dan perlengkapan multimedia. Termasuk didalamnya peralatan teleconferenceapabila menggunakan layanan synchronous learning melalui teleconference. 2) Sistem dan aplikasi Adaptive Hypermedia System Berbasis Moodle, yaitu sistem perangkat lunak yang mem-virtualisasi proses belajar mengajar konvensional yang meliputi bagaimana manajemen kelas, pembuatan materi atau konten, forum diskusi, sistem penilaian, sistem ujian dan segala fitur yang berhubungan dengan manajemen proses belajar mengajar. Sistem perangkat lunak tersebut sering disebut dengan Learning Management System (LMS). 3)Konten Adaptive Hypermedia System Berbasis Moodle, yaitu konten dan bahan ajar yang ada pada Adaptive Hypermedia System Berbasis Moodle dalam hal ini system yang digunakan mengunakan LMS (Learning Management System) Berbasis moodle. Konten dan bahan ajar dalam Adaptive Hypermedia System Berbasis Moodle dapat berbentuk multimedia-based content (konten berbentuk multimedia interaktif) atau text-based content (konten berbentuk teks seperti pada buku pelajaran biasa). Konten Adaptive Hypermedia System Berbasis Moodle biasa disimpan dalam LMS sehingga dapat diaksesoleh mahasiswa kapanpun dan di manapun.

Hubackova dan I. Semradova (2016) menyatakan Blended learning berkembang pesat di bidang akademik seperti di bidang perusahaan. Ini adalah salah satu yang kontemporer tren pendidikan. Pengajaran bahasa asing melalui e-Learning sering diikuti melalui lebih lambat dari e-Learning yang digunakan dalam mata pelajaran teknis atau sains. Di luar negeri pengajaran bahasa, oleh karena itu metode baru diterapkan secara bertahap. Metode itu sepertinya lebih cocok. Itu blended learning, yaitu kombinasi dari pengajaran kontak dengan seorang guru dan persiapan mandiri menggunakan pendidikan on-line.

Menurut Ahmad Luthfi (2006) sebuah sistem pembelajaran yang dikenal dengan LMS atau Learning Management System dapat difungsikan sebagai sebuah sistem yang cerdas dimana terdapat beberapa fasilitas yang diperoleh dari sistem ini. Penggunaan teori Ontology dan Semantic Web sangat berguna pada saat perancangan sistem karena dengan metode ini dapat membantu semua pihak apakah administrator, dosen, mahasiswa, dan 
komunitas lainnya untuk dapat mengakses sumberdaya dengan mudah dan terarah.

Sistem adaptive hypermedia dalam penelitian ini dikembangkan melalui Learning Management System (LMS) Moodle. Moodle merupakan salah satu LMS yang banyak digunakan pada dunia pendidikan karena user friendly digunakan untuk pembelajaran offline, online, bahkan dan dapat ditanam beberapa tambahan didalamnya seperti youtube, skype dan lain sebagainya, sebagaimana penjelasan Brusilovsky bahwa AH System dapat digunakan sepenuhnya dalam beberapa aplikasi dengan pengguna yang berbeda-beda tujuan dan pengetahuan.

Moodle merupakan Course Management System (CMS) atau LMS yang dikembangkan oleh Martin Dougiamas, seorang pendidik dan ahli komputer di University in Pert, Australia. dapat juga dimanfaatkan sebagai asisten digital dalam pembelajaran dan training, media evaluasi, dan cocok untuk pembelajaran dengan mengutamakan kompetensi dan pengetahuan seperti dunia kedokteran, sesuai dengan karakter vokasional/kejuruan. Saat ini moodle dapat diunduh pada laman http://www.moodle.org.

Menurut Novo-Corti, VarelaCandamio, \& Ramil-DíAz (2013) Penggunaan Teknologi Informasi dan Komunikasi dalam pendidikan tinggi telah terbukti menjadi sangat efektif dalam lingkungan pendidikan yang berbeda.

Faktor pendukung implementasi elearning menurut R. Irlanto Sudomo (2018) meliputi: fasilitas lab komputer tersedia sangat baik sehingga bisa dimanfaatkan baik dosen maupun mahasiswa dalam perkuliahan. Fasilitas jaringan internet dan wifi tersedia, dengan begitu baik dosen maupun mahasiswa dapat mengakses eliv elearning IKIP Veteran secara gratis. Sistem dan aplikasi elearning yang berupa perangkat lunak dalam hal ini Learning Management
System (LMS) sudah tersedia dengan baik dan bisa dimanfaatkan.

Ariesta Kartika Sari (2014) menyatakan Salah satu karakteristik belajar yang berkaitan dengan menyerap, mengolah, dan menyampaikan informasi tersebut adalah gaya belajar peserta didik. Gaya belajar merupakan modalitas belajar yang sangat penting. Informasi terkait karakteristik gaya belajar mahasiswa yang akan diajari, sangat penting bagi dosen untuk meningkatkan kualitas pembelajarannya.Mahasiswa juga akan lebih mudah memotivasi dirinya dalam pembelajaran.

Menurut Eni Rombe (2018) Gaya belajar merupakan pilihan seseorang dalam menerima dan memproses informasi yang diperolehnya. Gaya belajar yang memaksimalkan kerja otak kanan dan otak kiri memiliki kecenderungan dapat memproses informasi secara cepat.

Gaya belajar seseorang adalah kombinasi dari bagaimana seseorang menyerap dan mengatur serta mengolah informasi. Beberapa penelitian mengenai gaya belajar menunjuk kan bahwa (1) beberapa pelajar mempunyai kebiasaan belajar yang berbeda dengan yang lainnya, (2) beberapa pelajar belajar lebih efektif bila diajar dengan metode yang paling disukai, dan (3) prestasi pelajar berkaitan dengan bagaimana caranya belajar (Riding, 1998)

Menurut E. Handayani Tyas (2018) Ada 3 gaya belajar, yaitu : Visual diwujudkan dengan karakter suka membaca dan belajar dengan indera penglihatan/mata, kemudian Auditory ditunjukkan dengan karakter suka mendengarkan uraian guru di kelas maupun penjelasan orangtua saat mereka belajar, dan yang ke tiga Kinestetik ditunjukkan dengan suka belajar dengan mengalami secara langsung dan nyata yang sedang mereka pelajari.

\section{METODE PENELITIAN}

$\begin{array}{ccr}\text { Penelitian } & \text { ini } & \text { dilaksanakan } \\ \text { menggunakan } & \text { pendekatan } & \text { deskriptif }\end{array}$


kualitatif. Pada penelitian kualitatif, data yang diperoleh berupa informasi, keterangan dan hasil-hasil pengamatan lainnya tentang penelitian tersebut tidak diungkapkan dalam bentuk numerik, tetapi dalam bentuk katakata sesuai dengan karakteristik dari pendekatan kualitatif sehingga diperolah pemahaman yang mendalam dan lebih luas tentang pengamatan dibalik informasi selama berinteraksi di lapangan. Menurut Nana Syaodih Sukmadinata (2013) Penelitian kualitatif menggunakan desain penelitian studi kasus dalam arti peneliti difokuskan pada suatu fenomena yang ada baik yang bersifat ilmiah maupun rekayasa manusia kemudian dipilih dan ingin dipahami secara mendalam, dengan mengabaikan fenomenafenomena lainnya.

Penelitian yang dilakukan berupaya mendeskripsikan secara jelas mengenai implementasi Hypermedia System Berbasis Moodle di Universitas IVET. Dalam penelitian ini subjek penelitian adalah sekretaris program studi Pendidikan Teknik Mesin konsentrasi Otomotif (PTM-O) dosen, pengelola bagian TI dan mahasiswa yang sudah memanfaatkan Hypermedia System Berbasis Moodle pada Program Studi Pendidikan Teknik Mesin konsentrasi Otomotif Universitas Ivet. Objek penelitian ini adalah Implementasi Adaptive Hypermedia System Berbasis Moodle Untuk Mengatasi Keragaman, dalam pelaksanaan perkuliahan di program Studi Pendidikan Teknik Mesin konsentrasi Otomotif (PTMO) Universitas IVET. Secara eksplisit data yang hendak diperoleh antara lain tentang perencanaan, pelaksanaan dan penilaian dalam pembelajaran menggunakan Hypermedia System Berbasis Moodle. Oleh karena itu lebih tepat jika dijelaskan dengan deskripsi kata-kata untuk memperoleh makna, maka yang harus diteliti peneliti adalah mengaitkan informasi yang diperoleh dengan konteksnya. Sebelum memulai menentukan tempat penelitian terlebih dahulu peneliti mengadakan penjajagan dan penilaian lapangan (Moleong, 2007). observasi awal dilakukan untuk mendapatkan gambaran umum mengenai seperti keadaan tempat penelitian. Selain itu penjajagan awal dilakukan untuk memudahkan terciptanya hubungan yang baik dan akrab antara peneliti dengan subyek penelitian atau sumber informasi sehingga dapat diterima dengan baik dan dapat mengamati situasi yang wajar. Dengan demikian akan memudahkan peneliti dalam mendapatkan data mengenai informasi yang dikehendaki.

Metode yang digunakan untuk mengumpulkan data penelitian adalah 1) metode observasi, 2) metode wawancara, 3) metode dokumentasi. Antara satu metode dengan yang lain dilaksanakan untuk kepentingan saling mendukung dan saling melengkapi sehingga akan diperoleh data yang mendalam dan objektif. Metode-metode yang akan digunakan dalam penelitian ini dapat diuraikan sebagai Dalam penelitian kualitatif observasi merupakan alat pengumpul data utama. Observasi yang dilakukan guna memperoleh data mengenai implementasi dalam perkuliahan yang dilaksanakan di dalam kelas, dan ketersediaan sarana dan prasarana yang digunakan dalam pembelajaran. Untuk mengumpulkan informasi dari sumber data ini diperlukan metode wawancara. Metode wawancara ini merupakan metode yang paling banyak digunakan dalam penelitian kualitatif. Hal-hal yang menjadi pertanyaan dalam wawancara penelitian yang dilaksanakan ini antara lain mengenai Hypermedia System Berbasis Moodle, penerapan Hypermedia System Berbasis Moodle, tujuan penerapan elearning, peran dosen dan lain-lain. Wawancara dilaksanakan ini secara mendalam, maka digunakan pedoman wawancara. Dokumentasi merupakan pengumpulan data dengan melihat dan mencatat dokumen yang ada. Data yang diperoleh dari catatan 
lapangan antara lain mengenai sejarah berdirinya lembaga, visi misi dan tujuan lembaga, kegiatan perkuliahan dengan Hypermedia System Berbasis Moodle. Analisis data adalah proses menyusun data agar dapat ditafsirkan. Menyusun dapat berarti menggolongkannya dalam pola, tema atau kategori. Teknik analisis data yang digunakan meliputi tiga tahap, yaitu reduksi data (penyederhanaan), display data (disajikan) dan verifikasi atau penarikan kesimpulan. Teknik keabsahan data yang digunakan dalam penelitian ini adalah menggunakan teknik trianggulasi metode dan sumber. Trianggulasi adalah teknik pemeriksaan keabsahan data yang memanfaatkan sesuatu yang lain, digunakan untuk cross check data. Pengertian ini diterapkan pada saat ingin mengetahui manfaat implementasi Hypermedia System Berbasis Moodle di program studi Pendidikan Teknik Mesin konsentrasi Otomotif . Trianggulasi metode dilakukan dengan membandingkan hasil observasi dengan hasil wawancara. Trianggulasi sumber dilakukan dengan membandingkan hasil wawancara dosen dengan mahasiswa.

\section{HASIL DAN PEMBAHASAN}

Berdasarkan wawancara dengan ketua program studi gaya belajar mahasiswa Pendidikan Teknik Mesin konsentrasi Otomotif (PTM-O) memiliki latar belakang pendidikan yang heterogen, artinya mahasiswa yang masuk pada program studi Pendidikan Teknik Mesin konsentrasi Otomotif (PTM-O) terdiri dari lulusan SMA dan SMK, dengan begitu memiliki karakter yang berbeda-beda, untuk itu diperlukan sebuah metode belajar yang mampu mengatasi keragaman belajar tersebut.

Implementasi Adaptive Hypermedia System Berbasis Moodle Untuk Mengatasi Keragaman Gaya Belajar Pada Pendidikan Vokasi memberikan solusi bagi karakter kelas yang demikian. Menurut dosen sekaligus ketua program studi PTM-O pada aspek Visual Adaptive Hypermedia System Berbasis Moodle mampu menghadirkan solusi bagi siswa yag memiliki karakter karakter suka membaca dan belajar dengan indera penglihatan/mata moodle mampu menyampaikan materi dalam bentuk tulisan maupun gambar yang lebih mudah dipahami mahasiswa dengan tipe visual.

Adaptive Hypermedia System Berbasis Moodle juga mampu mengatasi mahasiswa dengan tipe Auditory yang memiliki karakter suka mendengarkan uraian dosen di kelas saat mereka belajar. Hal ini mampu dihadirkan dengan video streaming atau dengan penyampaian materi belajar dengan membuat konten video yang kemudian diuploads melalui Adaptive Hypermedia System Berbasis Moodle.

Pada aspek Kinestetik Adaptive Hypermedia System Berbasis Moodle memberikan pengalaman langsung dengan desain tutorial video yang didalamnya berisi petunjuk belajar praktikum, dengan begitu aspek kinestetik dapat terwujud dalam aktifitas belajar.

Implementasi Adaptive Hypermedia System Berbasis Moodle dimulai dengan mempersiapkan sarana dan prasarana berupa komputer yang ada di laboratorium menurut ketua unit IT Universitas IVET jumlah komputer yang ada sebanyak 33 unit, beserta jaringan internet yang tersedia dengan kecepatan 50 mbps. Dalam pembelajaran perkuliahan dengan Adaptive Hypermedia System Berbasis Moodle dosen harus membuat RPS sesuai dengan materi yang diajarkan. Menurut ketua program studi Pendidikan Teknik Mesin konsentrasi Otomotif, persiapan pembelajaran dengan menggunakan Adaptive Hypermedia System Berbasis Moodle dalam bentuk digital atau soft file, dengan demikian bisa diunggah dalam moodle dan dapat diunduh mahasiswa pada awal pembelajaran. Dalam RPS tersebut 
dosen juga harus menyiapkan bahan ajar yang akan disampaikan pada mahasiswa dengan disesuaikan gaya belajar mahasiswa meliputi aspek visual, Audiotory dan Kinestetik. Bahan ajar yang disiapkan dosen semua berbentuk digital baik file word, ppt, animasi, video, dan audio. Sebelum menggunakan Adaptive Hypermedia System Berbasis Moodle dosen diajarkan cara pemanfaatanya dalam pembelajaran.

Pelaksanaan pembelajaran dengan Adaptive Hypermedia System Berbasis Moodle diterapakan pada 5 mata kuliah sebagai implementasi awal. Dalam pelaksanaan pembelajaran dosen harus membuka portal dengan alamat web http://www.evodu.net/?redirect=0.

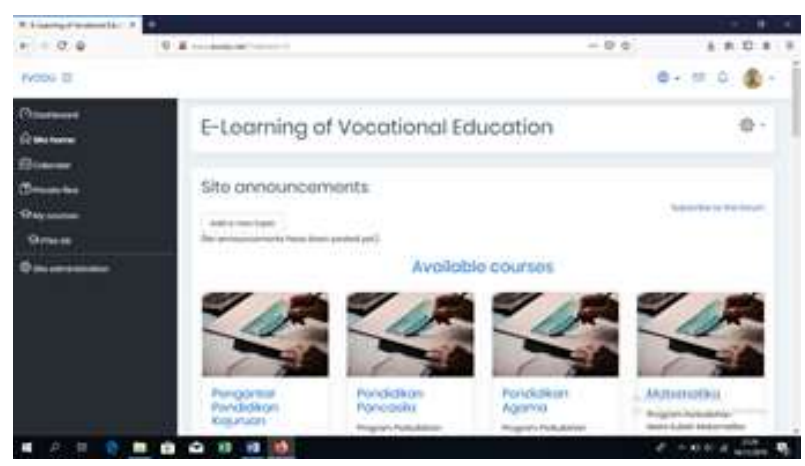

Gambar1.1. tampilan utama halaman Adaptive Hypermedia System Berbasis Moodle

Pada halaman Adaptive Hypermedia System Berbasis Moodle dosen melakukan aktifitas pembelajaran sesuai dengan mata kuliah yang diampu. Dosen mengunggah materi pada setiap pertemuan, hal ini dilakukan agar dosen dan mahasiswa melaksanakan pembelajaran sesuai waktu yang dijadwalkan. Menurut pemaparan ketua program studi Pendidikan Teknik Mesin konsentrasi Otomotif Materi yang diunggah dalam Adaptive Hypermedia System Berbasis Moodle bisa berupa file word, presentasi ppt, video, pdf maupun link

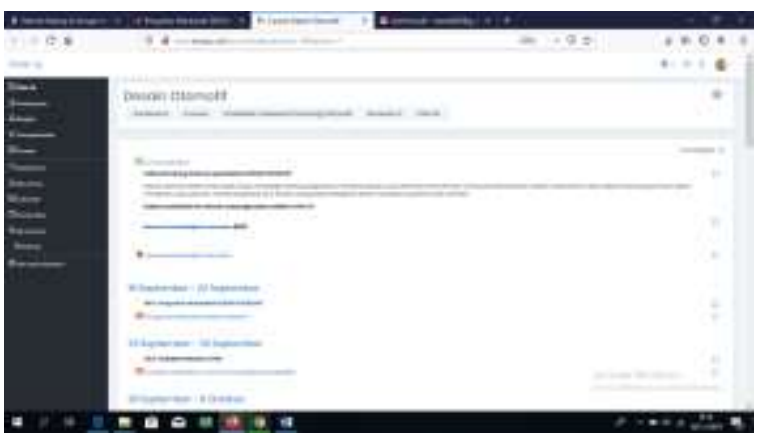

Gambar 1.2. Materi yang diunggah dalam Adaptive Hypermedia System

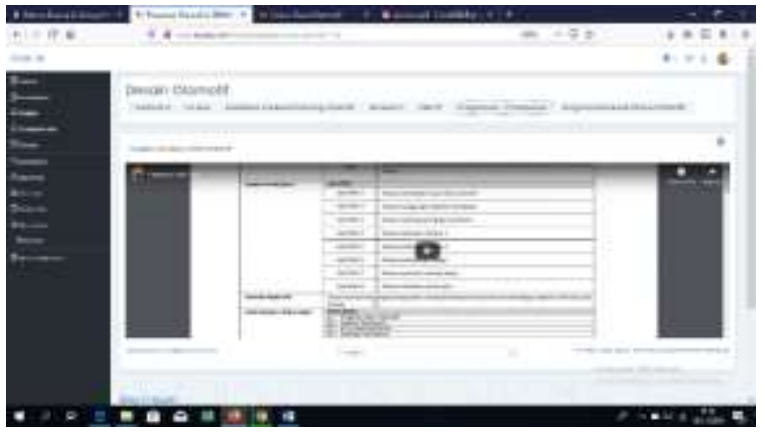

Gambar 1.3. Materi video yang diunggah dalam Adaptive Hypermedia System

Aktifitas mahasiswa mengakses portal Adaptive Hypermedia System Berbasis Moodle, selanjutnya mahasiswa registrasi agar diberi akses untuk mengikuti perkuliahan sesuai matakuliah yang diambil dalam KRS awal.

Sistem Penilaian dalam pembelajaran Adaptive Hypermedia System Berbasis Moodle bisa dilakukan menggunakan quiz. Menurut ketua program studi PTM-O dengan quiz interaktif maka akan memudahkan dosen dalam menilai karena setelah mahasiswa menjawab soal pertanyaan maka secara otomatis nilai keluar dengan sendirinya 


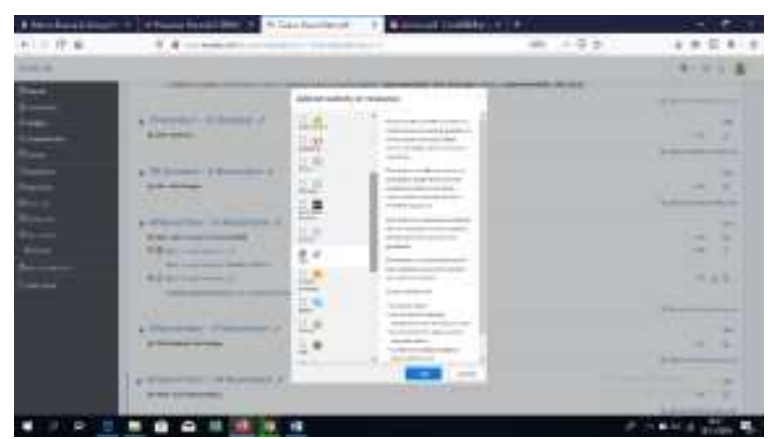

Gambar 1.4. Materi yang diunggah dalam Adaptive Hypermedia System

\section{PENUTUP}

Kesimpulan Adaptive Hypermedia System Berbasis Moodle sudah diterapakan pada 5 mata kuliah sebagai implementasi awal. Dalam implementasi Adaptive Hypermedia System Berbasis Moodle dosen harus menyiapkan terlebih dahulu RPS dan bahan ajar dalam bentuk digital. Setelah semua siap dosen memasukkan materi Adaptive Hypermedia System Berbasis Moodle melalui portal http://www.evodu.net/?redirect=0.

Sebelum aktifitas perkuliahan dosen mengunggah materi melalui http://www.evodu.net/?redirect=0. Sesuai dengan matakuliah yang diampu. Mahasiswa diberikan akses pada Adaptive Hypermedia System Berbasis Moodle

Penilaian perkuliahan pada Adaptive Hypermedia System Berbasis Moodle bisa dilakukan secara manual atau dengan quiz interaktif yang sudah disediakan.

\section{DAFTAR PUSTAKA}


Brusilovsky, P., Kobsa, A., \& Vassileva, J. (Eds.). (1998). Adaptive hypertext and hypermedia. Dordrecht: Kluwer Academic.

Hubackova, S., \& Semradova, I. (2016). Evaluation of blended learning. Procedia-Social and Behavioral Sciences, 217, 551-557.

Luthfi, A. (2006). Pemanfaatan Teori Semantic Web Pada Pengembangan Intelligent Learning Management System (ILMS). Jurnal Fakultas Hukum UII.

Moleong, L. J. (2007). Metode penelitian kualitatif.

Novo-Corti, I., Varela-Candamio, L., \& Ramil-DíAz, M. (2013). E-learning and face to face mixed methodology: Evaluating effectiveness of e-learning and perceived satisfaction for a microeconomic course using the Moodle platform. Computers in Human Behavior, 29(2), 410-415.

Rombe, E. (2018). Implementasi Karakteristik Gaya Belajar (4 Mat System) Peserta Didik Prodi Pendidikan Agama Kristen Di Stt Kristus Alfa Omega, Semarang Tahun Ajaran 2017/2018. Shift Key: Jurnal Teologi dan Pelayanan, 8(1).

Riding, R., \& Rayner, S. 1998. Cognitive styles and learning strategies. London: David Fulton Publisher

Sari, A. K. (2014). Analisis Karakteristik Gaya Belajar VAK (Visual, Auditorial, Kinestetik) Mahasiswa Pendidikan Informatika Angkatan 2014. Edutic-Scientific Journal of Informatics Education, 1(1).

Sudomo, R. I. (2018). Implementasi ELearning pada Program Studi Pendidikan Informatika Ikip Veteran
Jawa Tengah. Joined Journal (Journal of Informatics Education), 1(1), 3243.

Tyas, E. H. (2018). MENGENALI GAYA BELAJAR PESERTA DIDIK. Jurnal Manajemen Pendidikan, 5(2), 249258. 